\title{
How should Helicobacter pylori positive dyspeptic patients be managed?
}

\author{
N J Talley
}

\begin{abstract}
Introduction
Dyspepsia, according to the internationally accepted Rome criteria, refers to pain or discomfort centred in the upper abdomen; patients with predominant heartburn are excluded from this group, although minor or infrequent heartburn is commonly associated with dyspepsia. ${ }^{1}$ It is an important condition not only because it is common and costly, but because it may indicate the presence of serious disease such as peptic ulcer or gastric cancer. ${ }^{2-4}$ However, the most frequent causes of dyspepsia are functional dyspepsia and gastrooesophageal reflux disease. ${ }^{2-4}$ The discovery of Helicobacter pylori has resulted in important advances in the management of dyspepsia. The clinician faced with a patient who has persistent or recurrent dyspepsia needs to differentiate clearly those patients who have not been previously investigated from patients documented to have functional dyspepsia after investigation (fig 1). Here, the management of $H$ pylori positive dyspeptic patients who have and have not been fully investigated will be reviewed.
\end{abstract}

\section{Uninvestigated dyspepsia}

In new patients with dyspepsia who have alarm features (such as older age at first onset $(>50$ years), regular ingestion of non-steroidal antiinflammatory drugs, or symptoms such as weight loss, dysphagia or bleeding) or a fear of serious disease, prompt upper endoscopy is always indicated if available. ${ }^{56}$ In younger patients without alarm features, management options include a trial of empirical therapy, prompt endoscopy for all, $H$ pylori testing followed by endoscopy in positive cases, and

Medicine, University

of Sydney, Nepean

Hospital, Penrith 2751, Australia testing for $H$ pylori and treatment of those patients found to be infected with the bacterium.

Early endoscopy does have some advantages. It is more accurate than a barium meal and biopsy specimens can be taken to detect $H$ pylori as well as from any suspicious areas to rule out malignancy. ${ }^{5}$ Peptic ulcer can be identified and then adequately managed. It is also more reassuring to patients than empirical therapy. ${ }^{7}$ However, endoscopy is also expensive and cancer is rarely found in otherwise healthy dyspeptic patients. ${ }^{5}$ Moreover, endoscopy is often delayed because of waiting lists or carried out when patients are on ulcer medications; this may lead to an erroneous diagnosis of functional dyspepsia in patients with ulcer disease or oesophagitis.

The practice of testing for $H$ pylori in younger patients with new onset dyspepsia who do not have alarm features is becoming more widespread. ${ }^{5-12}$ A number of studies from Europe as well as New Zealand have reported that among dyspeptic patients who are infected with $H$ pylori, between 20 and $60 \%$ have an underlying peptic ulcer at endoscopy (fig 2). ${ }^{13-21}$ In view of the overwhelming evidence that eradication of $H$ pylori eliminates the ulcer diathesis, ${ }^{9-12}$ treatment of $H$ pylori in these cases is very likely to be of value. Moreover, some without ulcer disease are likely to develop the condition over a lifetime so treating these cases now may be useful. ${ }^{22}$ However, it is not firmly established that those who are dyspeptic and have the infection are significantly more likely to develop an ulcer than those with the infection who are symptom-free. In Western countries patients with dyspepsia who do not have alarm features also have a very low probability of serious structural disease, including gastric cancer. ${ }^{23} 24$

This knowledge has led to the concept that testing for $H$ pylori and treating all infected cases (test and treat) should be efficacious because it will largely eliminate the pool of ulcer patients. The preliminary results of controlled trials have in general supported the safety and efficacy of a test and treat approach. Heaney et al randomised $104 \mathrm{H}$ pylori positive patients based on breath testing to empirical eradication therapy without endoscopy or endoscopy with treatment based on the results. ${ }^{25}$ Overall, $25 \%$ in the empirical eradication therapy group proceeded to endoscopy because of no improvement in dyspepsia over six months. Symptom scores improved in both arms by six months but were significantly better in the empirical therapy group. ${ }^{25}$ Jones et al randomised 233 patients to $H$ pylori test and treat or endoscopy. ${ }^{26}$ Only $12 \%$ of patients in 


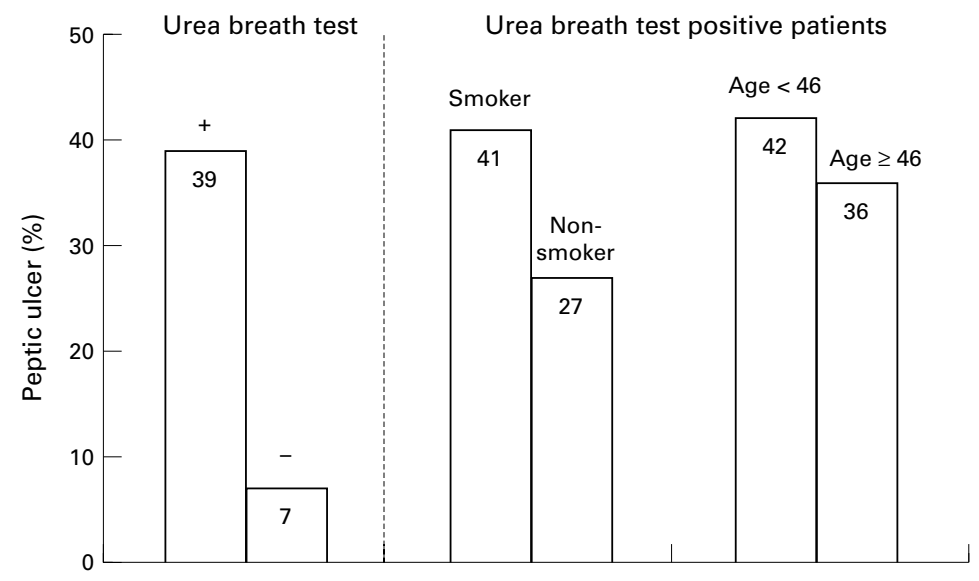

Figure 2 Prevalence of peptic ulcer in dyspeptic patients presenting for endoscopy. Data from reference $21 .+$, positive test; - , negative test.

the test and treat arm underwent endoscopy by one year but no ulcers or cancers were identified. In the test and treat arm there were more referrals to specialists and for investigation, but the costs of treatment were significantly lower in this group. Duggan et al compared four strategies: immediate endoscopy $(\mathrm{n}=151)$, empirical lansoprazole $(\mathrm{n}=140)$, H pylori test and endoscopy if positive $(\mathrm{n}=152)$, and $H$ pylori test and treat $(\mathrm{n}=154$ tested and $\mathrm{n}=39$ treated). ${ }^{27}$ Overall, $24 \%$ randomised to empirical lansoprazole required endoscopy by six months; this was similar to the endoscopy rate in the $H$ pylori negative and positive patients in the test and treat arm, where $17 \%$ and $31 \%$, respectively, underwent endoscopy during follow up. However, the rapid whole blood $H$ pylori test used may have been suboptimal. ${ }^{27}$ Lassen et al randomised 500 patients to prompt endoscopy or test and treat. ${ }^{28}$ There were no differences between the groups in the number of symptom-free days, overall symptom severity or rates of sick leave at one year. Patient satisfaction was marginally, albeit significantly, greater in the endoscopy arm ( $56 \%$ very satisfied in test and treat versus $62 \%$ in the endoscopy group). These results all suggest that the outcome with a test and treat strategy is similar to the outcome applying a more expensive prompt endoscopy strategy.



Figure 3 Relief of dyspepsia in three randomised controlled trials with 12 months' follow up. Data from references 33-35.
A number of prestigious working parties have recommended, based on present evidence, that test and treat represents optimal clinical practice. ${ }^{5-12}$ However, there are limitations that clinicians need to keep in mind. The predictive value of diagnostic testing for $H$ pylori peptic ulcers (arguably the key condition that test and treat addresses) depends on the sensitivity and specificity of the test as well as the prevalence of the disease in the population being assessed..$^{29}$ The sensitivity and specificity of serology varies notably, and only a locally validated test with at least $90 \%$ sensitivity and specificity for the infection should be relied upon. ${ }^{10}$ Urea breath testing has produced consistently superior results compared with serology in the published literature. ${ }^{13}{ }^{21}$ However, even if the test is excellent, the predictive value for relevant disease may be poor. For example, if the prevalence of $H$ pylori infection in dyspepsia is $40 \%$ but only one in $10 \mathrm{H}$ pylori positive cases has an ulcer, then the positive predictive value of the test for ulcer disease (with 95\% sensitivity and specificity for $H$ pylori) is only $45 \%$, compared with $90 \%$ if four in $10 \mathrm{H}$ pylori infected dyspeptic patients have ulcer disease. With a rise in $H$ pylori negative ulcers in some parts of the world and the declining incidence of $H$ pylori overall in Western countries, ${ }^{30}$ the value of a test and treat strategy will need careful scrutiny and likely revision in the future.

\section{Investigated dyspepsia}

The first question to address is should all patients with dyspepsia undergoing endoscopy, the "gold standard" investigation to exclude clinically relevant pathology, be tested for $H$ pylori if no clear explanation such as a peptic ulcer is discovered? The next question to consider is should all infected patients with functional dyspepsia should be offered eradication therapy? The answers to these questions are controversial because of the limitations of the available evidence.

The key issue is whether identification and cure of $H$ pylori cures the symptoms of functional dyspepsia. Older short term studies provided disparate results and have been roundly criticised. ${ }^{31}{ }^{32}$ However, new well designed trials have not yet provided a definitive answer. In the past year, large trials have reported new results (fig 3). McColl et al from Scotland reported the findings from a single centre randomised controlled trial of 318 patients. They compared triple therapy (omeprazole, metronidazole and amoxicillin) with omeprazole for one week, with 12 months' follow up..$^{33}$ Overall, $87 \%$ in the active treatment group were cured of the infection compared with $4 \%$ on placebo. At one year, $21 \%$ had symptom relief in the $H$ pylori treatment arm compared with $7 \%$ in the comparison group, a significant difference. The investigators concluded that one in five patients with functional dyspepsia will benefit from eradication therapy. ${ }^{33}$ However, the results from equally well conducted multicentre trials have reached different conclusions (fig 3). Talley et al conducted a trial in Europe and Australasia; 
275 patients were randomised to triple therapy (omeprazole, clarithromycin and amoxicillin) or placebo for one week and followed for one year. ${ }^{34}$ An eradication rate of $84 \%$ and $4 \%$ was achieved in the triple therapy and placebo arms, respectively. At one year, $24 \%$ on active treatment and $21 \%$ on placebo had relief of dyspepsia, a non-significant difference. ${ }^{34}$ Similarly, Blum et al randomised 348 patients to triple therapy or omeprazole for one week, and then followed patients for one year. Overall, $27 \%$ on active treatment and $21 \%$ on placebo had symptom relief, a difference that failed to reach significance. ${ }^{35}$ Koelz et al randomised 181 patients with $H$ pylori who had failed to respond to treatment with proton pump inhibitors; they received either omeprazole and amoxicillin or omeprazole for two weeks, and were followed for six months. In this selected population, the proportion of responders was almost identical in each arm although data on symptom relief were not provided. ${ }^{36}$ The new trial results generally suggest that $H$ pylori eradication is no more successful than placebo in relieving functional dyspepsia. Hence, a test and treat strategy for $H$ pylori cannot rely on providing benefits in cases of functional dyspepsia, who usually comprise the majority of patients suffering from dyspepsia.

Working parties have generally recommended that $H$ pylori infected patients with functional dyspepsia be offered treatment on a case-by-case basis, after careful explanation of the risks and benefits. ${ }^{5-12}$ This translates into begrudging acceptance that most clinicians will offer treatment to these people once infection is documented, despite some lingering concerns about rising antibiotic resistance rates and side effects of treatment in addition to the lack of efficacy in functional dyspepsia. ${ }^{32}$ Unexpected long term outcomes also need to be considered. For example, the risk of reflux oesophagitis may be increased in duodenal ulcer patients cured of $H$ pylori infection, ${ }^{37}$ although recent data suggest that this is not a major concern in functional dyspepsia. ${ }^{38}$ The potential benefits of treating functional dyspepsia are prevention of peptic ulcer complications and cancer in the future. ${ }^{22}$ Patients, once told they have an infection that can cause ulcer or cancer, are unlikely not to want treatment no matter how remote the risk. Although theoretical calculations have been performed that suggest such an approach is valuable (with lifetime mortality rates calculated to be as high as one in 35 for men and one in 65 for women who are infected), the benefits really remain to be established..$^{22}$ For example, no one knows at what timepoint the clock can be turned back to prevent progression to cancer. This is crucial when calculating cost effectiveness ${ }^{39}$; it may be that once any degree of gastric atrophy is established, it is too late and cure of $H$ pylori then does not change the natural history. Hence, if you do not wish to treat (or be caught on the horns of a dilemma), do not test!

\section{Conclusions}

The management of $H$ pylori positive dyspeptic patients has now changed; in general, there is widespread acceptance that treatment of the infection should represent first line therapy in those who do not require further investigation, including endoscopy. There is also an increasing trend to offer eradication therapy to $H$ pylori infected patients with documented functional dyspepsia, despite the lack of a clear benefit on relief of dyspepsia in recent trials. However, cost effective strategies need to be put in place when symptoms fail to resolve or there is only temporary relief. Trials specifically targeted at those who have failed to obtain symptom relief after $H$ pylori eradication have still to be undertaken.

1 Talley NJ, Colin-Jones D, Koch KL, et al. Functional dyspepsia: A classification with guidelines for diagnosis and management. Gastroenterol Int 1991;4:145-60.

2 Richter JE. Dyspepsia: organic causes and differential characteristics from functional dyspepsia. Scand $\mathcal{F}$ Gastroenterol 1991;(suppl 182):11-16.

3 Heikkinen M, Pikkarainen P, Takala J, et al. Etiology of dyspepsia: four hundred unselected consecutive patients in general practice. Scand 7 Gastroenterol 1995;30:519-23.

4 Klauser AG, Voderholzer WA, Knesewitsch PA, et al. What is behind dyspepsia? Dig Dis Sci 1993;38:147-54.

5 Talley NJ, Silverstein M, Agreus L, et al. AGA Technical Talley NJ, Silverstein M, Agreus L, et al. AGA Technical
Review: Evaluation of dyspepsia. Gastroenterology 1998; 114:582-95.

6 American College of Physicians. Endoscopy in the evaluation of dyspepsia. Ann Intern Med 1985;102:266-9

7 Bytzer P, Hansen JM, Schaffalitzky de Muckadell OB. Empirical $\mathrm{H}_{2}$-blocker therapy or prompt endoscopy in management of dyspepsia. Lancet 1994;343:811-16.

8 Axon ATR. Chronic dyspepsia: who needs endoscopy? Gastroenterology 1997;112:1376-80.

9 Malfertheiner P, Megraud F, O'Morain C, et al. Current European concepts in the management of Helicobacter pylori infection - the Maastricht Consensus report. Eur $\mathcal{F}$ pylori infection - the Maastronterol Hepatol 1997;9:1-2.

10 Lam SK, Talley NJ. Report of the 1997 Asia Pacific Consensus Guidelines on the management of $\mathrm{H}$ pylori. $\mathcal{F}$ Gastroenterol Hepatol 1998;13:1-12.

11 Hunt RH, Thompson ABR. Canadian Helicobacter pylori consensus conference. Can f Gastroenterol 1998;12:31-41

12 Howden CW. For what conditions is there evidence-based justification for treatment of Helicobacter pylori infection? Gastroenterology 1997;113(suppl 6):S107-12

13 McColl KEL, El-Nujumi A, Murray L, et al. The Helicobacter pylori breath test: a surrogate marker for peptic ulcer disease in dyspeptic patients. Gut 1997;40:302-6.

14 Mendall MA, Jazrawi RP, Marrero JM, et al. Serology for Helicobacter pylori compared with symptom questionnaires in screening before direct access endoscopy. Gut 1995;36:330-3.

15 Patel P, Khulusi S Mendall MA, et al. Prospective screening of dyspeptic patients by Helicobacter pylori serology. Lancet 1995;346:1315-18.

16 Vaira D, Stanghellini V, Menegatti M, et al. Prospective screening of dyspeptic patients by Helicobacter pylori screening of dyspeptic patients by Helicobacter
serology: a safe policy? Endoscopy 1997;29:595-601.

17 Fraser AG, Ali MR, McCullogh S, et al. Diagnostic tests for Fraser AG, Ali MR, McCullogh S, et al. Diagnostic tests for
Helicobacter pylori - can they select patients for Helicobacter pylori - can they sele
endoscopy? NZ Med $\mathcal{F} 1996 ; 109: 95-8$.

18 Collins JSA, Bamford KB, Sloan JM, et al. Screening for Helicobacter pylori antibody could reduce endoscopy workload in young dyspeptic patients. Eur $\mathcal{F}$ Gastroenterol Hepatol 1992;4:991-3.

19 Heikkinen M, Hanatuinen E, Mayo K, et al. Usefulness of anti-Helicobacter pylori and anti-cagA antibodies in the selection of patients for gastroscopy. Am $\mathcal{F}$ Gastroenterol 1997;92:2225-9.

20 Mendall MA, Goggin PM, Marrero JM, et al. Role of Helicobacter pylori serology in screening prior to endoscopy. Eur 7 Gastroenterol Hepatol 1992;4:713-17.

21 Mowat C, Murray L, Hilditch TE, et al. Comparison of Helisal rapid blood test and ${ }^{14} \mathrm{C}$-urea breath test in determining Helicobacter pylori status and predicting ulcer determining Helicobacter pylori status and predicting ulcer disease 20 .

22 Axon A, Forman D. Helicobacter gastroduodenitis: a serious infectious disease. $B M \mathcal{F}$ 1997;314:1430-31.

23 Williams $\mathrm{B}$, Luckas $\mathrm{M}$, Ellingham $\mathrm{JH}$, et al. Do young patients with dyspepsia need investigation? Lancet 1988;ii: 1349-51.

24 Christie J, Shepherd NA, Codling BW, et al. Gastric cancer below the age of 55: implications for screening patients with uncomplicated dyspepsia. Gut 1997;41:513-17.

25 Heaney A, Collins JSA, Watson RGP, et al. A prospective randomised trial for a test and treat policy versus gastroscopy in young $\mathrm{H}$ pylori positive dyspeptic patients [abstract]. Gut 1998;42(suppl 1):A17.

26 Jones RH, Tait CL, Sladen G, et al. A Helicobacter test and treat strategy: costs and outcomes in a randomised controlled trial in primary care [abstract]. Gut 1998;42(suppl led trial
$1):$ A81. 
27 Duggan A, Elliott C, Logan RPH, et al. Does near patient H. pylori testing in primary care reduce referral for endos-
copy? Results from a randomised trial [abstract]. Gut copy? Results from a

28 Lassen AT, Pedersen FM, Bytzer P, et al. H. pylori test and treat or prompt endoscopy for dyspeptic patients in primary care. A randomized controlled trial of two management strategies: one year follow-up [abstract]. Gastroenterology 1998;114:A196.

29 Agreus L, Talley N. Challenges in managing dyspepsia in general practice. BMF 1997;315:1284-8.

30 Xia H H-X, Talley NJ, Keane CT, et al. Recurrence of Helicobacter pylori infection after successful eradication: nature, possible causes and potential preventive strategies. Dig Dis Sci 1997;42:1821-34.

31 Talley NJ. A critique of therapeutic trials in Helicobacter pylori-positive functional dyspepsia. Gastroenterology 1994; pylori-positive

32 Veldhuyzen van Zanten S, Talley NJ. Should antibiotic treatment of Helicobacter positive patients within non-ulcer dyspepsia now be recommended? Eur f Gastroenterol Hepadyspepsia now be reco

33 McColl KEL, Murray L, El-Omar E, et al. Symptomatic benefit from eradicating Helicobacter pylori infection in patients with nonulcer dyspepsia. N Engl f Med 1998;339. 1869-74.
34 Talley NJ, Janssens J, Lauritsen $\mathrm{K}$, et al. Eradication of Helicobacter pylori in functional dyspepsia: randomised double blind controlled trial with 12 months' follow up. BMF 1999;318:833-7.

35 Blum AL, Talley NJ, O'Morain C, et al. Lack of effect of treating Helicobacter pylori infection in patients with nonulcer dyspepsia. N Engl f Med 1998;339:1875-81.

36 Koelz HR, Arnold R, Stolte M, et al. Treatment of Helicobacter pylori (HP) does not improve symptoms of functional dyspepsia (FD) [abstract]. Gastroenterology 1998;114:A182.

37 Labenz J, Blum AL, Bayerdorffer E, et al. Curing Helicobacter pylori infection in patients with duodenal ulcer may provoke reflux esophagitis. Gastroenterology 1997;112:1442-7.

38 Talley NJ, Janssens J, Lauritsen K, et al. No increase of reflux symptoms or esophagitis in patients with non-ulcer dyspepsia 12 months after Helicobacter pylori eradication. A randomized double-blind placebo-controlled trial [abstract]. Gastroenterology 1998;114:A1250.

39 Parsonnet J, Harris RA, Hack HM, et al. Modelling cost-effectiveness of Helicobacter pylori screening to prevent gastric cancer: a mandate for clinical trials. Lancet 1996;348:150-4. 